\title{
Urban solid waste generation pattern and health in mid-21st century in Nigeria
}

\author{
J. A. Adelegan \\ Department of Civil Engineering, \\ University of Ibadan, \\ Ibadan, Oyo State, \\ Nigeria.
}

\section{Abstract}

The rapid growth of urban centres in Nigeria, coupled with the development of unstructured infrastructural and social services have created an environmental situation in many parts of the country which is becoming increasingly inimical to healthy living. Considering the paucity of basic data on urban solid waste generation for effective management with the attendant health impacts. This study was established to estimate solid waste generation pattern in Nigerian urban centres as a step towards effective waste management planning for improved health and better living conditions in the mid-21st Century

Data used for the work was largely obtained from 1982 field survey of the then Environmental Planning and Protection Division of the Federal Ministry of bbHousing and Environment. A computer software, "Econometric Views for Windows (Micro TSP)" was utilised to obtain the modelling equation by running an ordinary least square regression (OLS). An estimated domestic solid waste generation volume for planning horizon 2050 was computed using spreadsheet applications. The estimated volume of domestic solid waste generation by 2050 is a clear evidence that the magnitude of waste likely to be generated in Nigerian urban centres and mega-cities are bound to be enormous.

Hence, unless some drastic changes takes place in the technological, organisational and financial arrangements for dealing with this vastly increased volume, environmental condition in Nigerian urban centres and mega-cities promise to suffer degradation even more drastically in the mid- $21^{\text {st }}$ Century. 


\section{Introduction}

The role of health in the socio-economic development of a nation cannot be overemphasised. Health is a precondition for socio-economic development being viewed as a by-product of economic development.

Good health is both a crucial part of human well being and an important economic input into the development process (World Bank [1]). Economist are concerned with the quality of the environment because it is a key determinant of health status and hence productivity.

However, cities in developing countries are increasingly becoming unhealthy places to live, with local governments lacking the capacity to collect and dispose solid waste. Infrastructure and services are often unable to keep pace with the discharge of pollutants, and the concentration of waste overwhelms the assimilative capacity of natural ecosystems within city boundaries.

The problems will be compounded as rapid urbanisation continues in the third millenium. Due to urbanisation pressure, some refuse disposal sites soon become part of the cities. The pollution of surface and groundwater litter problem is also widespread (Holmes [2]).

Of all the costs of urban environmental degradation, damage to human health is by far the highest. There is a direct link between urban environmental degradation and public health in terms of water-related diseases such as diarrhea, dysentery, cholera and typhoid.

The rapid growth of urban centres in Nigeria, coupled with the development of unstructured infrastructural and social services have created an environmental situation in many parts of the country which is becoming increasingly inimical to healthy living. The resulting situation, especially with respect to the provision of modern services such as solid waste collection and disposal, deteriorates progressively with increasing size in a cumulative process of management problems.

All kinds of organisational and administrative experiments have been tried to grapple with this increasing problem of urban environmental management, especially with respect to solid waste. The problem has not only defied all such experiments, it has indeed become more confounded and compounded (FMHE [3]).

One of the major problems of solid waste management in Nigerian urban centres is the institutional framework (Osuocha [4]). This is mainly due to paucity of reliable data on the generation rate and characterisation of solid waste and the inability to appreciate the health hazards posed by solid waste mismanagement.

In Nigeria, house to house collection of solid waste is uncommon hence individuals are required to deposit their solid waste at refuse depots where vehicles can collect them for final disposal. However, there is no regular routine collections and as a result, the communal points referred to as dumps become nuisance points to urban dwellers. The hazards arising from generation of solid 
waste has generally been of great concern to environmental health engineers in developing countries.

\section{Rationale for the study}

Patronage of hospitals and other health care facilities in Nigeria is on the increase. The rapidly increasing population coupled with the deteriorating environment are some of the factors responsible for this trend (Sangodoyin [5]). Hospital records have confirmed high incidence of typhoid, cholera, dysentery, infectious hepatitis and guinea worm in urban settlements of Nigeria.

The cheapest and easiest way to dispose solid waste is by dumping on a piece of land provided for the purpose. The method has always been found satisfactory (Pickford [6]). The mismanagement of dumpsites however could result in extensive water pollution.

It is also common for food crops to be planted along the banks of streams passing through or very close to badly managed landfills. Landfill sites are sometimes used as farms. The streams or rivers are sometimes used to irrigate farms.

Incidences of water-borne diseases in developing countries leading to millions of deaths, have been reported (UNU [7]). Some of these deaths have been traced to the use of waters, grossly polluted by untreated sewage and mismanaged solid waste, for domestic activities (UNEP [8]).

Kajogbola [9] revealed the prominence of malaria, dysentery, chicken pox, measles and pneumonia as the greatest causes of morbidity within the Ibadan region in Nigeria. The study also revealed that the leading killer diseases in the region are solid waste management related precipitated by ignorance, poverty and low standard of living as shown in Table 1 below;

The morbidity pattern shown in Table 1 was also found to be applicable to the larger Nigerian urban society since solid waste management problem is not peculiar to a particular region but a common feature in every urban community in Nigeria. 
Table 1 Ten top diseases from sampled hospital records in Ibadan, Nigeria

\begin{tabular}{llcl}
\hline Rank & Type of Disease & Recorded Cases & \% of Total \\
\hline 1 & Diarrhea & 1530 & 25.0 \\
2 & Malaria & 1130 & 18.5 \\
3 & Pneumonia & 713 & 11.7 \\
4 & Tuberculosis & 686 & 11.2 \\
5 & Eye Disease & 459 & 7.5 \\
6 & Measles & 421 & 6.9 \\
7 & Malnutrition & 330 & 5.4 \\
8 & Anaemia & 318 & 5.2 \\
9 & Hypertension & 314 & 5.1 \\
10 & Hernia & 219 & 3.5 \\
& Total & 6120 & 100 \\
\hline
\end{tabular}

Source: Kajogbola [9], Nigeria Environmental Study Action Team

Sources close to the National Health Policy in the Federal Ministry of Health gave the morbidity pattern in Nigeria as follows;

Table 2 General morbidity pattern in Nigeria

\begin{tabular}{llc}
\hline Rank & Morbidity & Percentage \\
\hline 1 & Infectious and Parasitic diseases & 38.2 \\
2 & Respiratory Diseases & 12.7 \\
3 & Diseases of Nervous Systems & \\
& and Organs & 9.9 \\
4 & Ill-Defined Conditions & 9.2 \\
5 & Skin Diseases & 8.4 \\
6 & Digestive System & 4.7 \\
7 & Accident & 3.1 \\
8 & Muscle and Skeletal Diseases & 2.9 \\
9 & Genito-Urinary Diseases & 2.9 \\
10 & Blood Diseases-Anaemia & 2.5 \\
11 & Nutritional and Metabolic Diseases & 1.8 \\
12 & Others & 3.7 \\
& Total & 100 \\
\hline
\end{tabular}

Source: Federal Ministry of Health [FMH][10]

The final disposal of solid waste is often in excavated pits or natural gullies in Nigeria. In a few cases, refuse are incinerated. The use of dumps, as a mode of waste disposal is seen as a means of reclaiming natural gullies and excavation. 
The effects of such uncontrolled disposal system renders surface waters and the groundwater systems unsafe for human, agricultural and recreational use, destroys biotic life, poisons the natural ecosystems, poses a threat to human life and is therefore against the principles of sustainable development (Benka-Coker and Bafor [11])

There is the need to initiate and implement elaborate and bold plans for evacuating solid waste in order to live within a cleaner environment. Moreover, experience from advanced industrialised countries have shown that in the short term, the net effect of environmental control activities are almost certain to have some macroeconomic impacts.

Considering the paucity of basic data on urban solid waste generation for effective management and the health impacts of solid waste mismanagement. This study is strategic and also timely as we move into the new millenium to;

(a) Estimate solid waste generation pattern in Nigerian urban centres as a step towards effective waste management planning for improved health and better living conditions in the mid- $21^{\text {st }}$ Century

(b) Use the result of the estimation to establish management criteria and strategies for solid waste collection, storage and disposal in the mid$21^{\text {st }}$ Century.

(c) Suggest policy recommendations on how to minimise environmental pollution by solid waste mismanagement.

\section{Methodology}

The work covers 15 Nigerian urban centres (state capital and key urban centres). Nigeria has a land area of 923,768 square kilometers (FOS [12]) with per capita income of U.S $\$ 358$ (1998) and a population of 121.77 million people (1998) (ECA [13]) out of which $63 \%$ live in rural areas while $37 \%$ reside in urban areas (UNPF [14]).

The author employed the secondary source of data collection due to the scope of coverage of the work ( 15 urban centres), constraints of finances and logistics. Data used includes the 1963 and 1991 population of states of Nigeria by local government areas obtained from the National Population Commission.

Other data used for the work includes the 1982 per capita per day solid waste generation rate and the 1982 solid waste generation by land-use types in Nigerian urban centres obtained from 1982 field survey of the then Environmental Planning and Protection Division of the Federal Ministry of Housing and Environment.

Other data used for the work includes the population, demographic, social and economic indicators (urban growth rate and urban percentage for Nigeria) obtained from "The State of the World Population (1994)" published by the United Nations Population Fund.

A computer software, "Econometric Views for Windows (Micro TSP)" was utilised to obtain the modelling equation by running an ordinary least square regression (OLS) for the 1982 estimated domestic solid waste generation 


\section{Environmental Health Risk}

volume with the estimated 1982 population. An estimated domestic solid waste generation volume for planning horizon 2050 was computed using spreadsheet applications. Based on the estimated generation volume, policy recommendations were suggested on how to minimise environmental pollution caused by solid waste mismanagement.

\section{Data analysis and estimating issues}

The volume and complexity of solid waste in Nigerian urban centres up to 2050 are likely to be influenced by population size, the standard of living of the inhabitants and the level of land-use differentiation in the city, that is the proportion of the city devoted to residential, commercial, and industrial uses (Oluwande [15]).

To these may be added the eating habits, aesthetic standards and other cultural characteristics of the people. In addition, there are such factors as proximity to disposal sites, accessibility, transportation facilities, streets layouts and composting of waste which do all affect the generation rate of solid waste.

The variables likely to determine the volume of solid waste generated in a city, lead naturally to an estimation equation of the type:

$Y=b_{0}+b_{1} X_{1}+b_{2} X_{2}+b_{3} X_{3}++b_{n} X_{n}$

However, the range of data needed to operationalise such an equation has not been possible to collect given the scope of coverage of the work (15 urban centres), time constraint, constraint of finances and logistics. But it can be inferred rightly that the interplay of all these factors produced the per capita per day rate.

The estimation is then based on the resolution of a simple linear equation of the type:

$Y=b_{0}+b_{1} X$

which uses the size (population) of city (X) as the independent variable and the estimated volume of waste domestic solid waste generation volume with the estimated 1982 population generated $(\mathrm{Y})$ as the dependent variable. The approach expects that nothing is seriously expected to change except the internal factor of increased structural complexity with increasing size as the city grows.

The population growth rate as a major element in our estimation can be obtained using the geometric growth rate of a biological community equation of the type: 
Table 3 Estimated 2050 solid waste generation pattern for Nigerian urban centres

\begin{tabular}{lcccccccc}
\hline Urban Centres & $\mathrm{P}_{1963}$ & $\mathrm{~K}$ & $\mathrm{t}$ & $\mathrm{GRCD}_{1982}$ & $\mathrm{EP}_{1982}$ & EDGV $_{1982}$ & $\mathrm{EP}_{2050}$ & $\mathrm{EDGV}_{2050}$ \\
\hline Lagos & 665,000 & 0.055 & 19 & 0.34 & 1890858.69 & 234655.56 & 79601150 & 10180107.83 \\
Ibadan & 627,000 & 0.055 & 19 & 0.39 & 1782809.62 & 253782.95 & 75052513 & 9599033.079 \\
Kano & 295,000 & 0.055 & 19 & 0.33 & 838801.975 & 101033.7 & 35311788 & 4522274.73 \\
Kaduna & 150,000 & 0.055 & 19 & 0.66 & 426509.479 & 102746.13 & 17955147 & 2305015.812 \\
Onitsha & 163,000 & 0.055 & 19 & 0.39 & 463473.634 & 65975.472 & 19511259 & 2503804.542 \\
Port-Harcourt & 180,000 & 0.055 & 19 & 0.54 & 511811.374 & 100878.02 & 21546176 & 2763759.036 \\
Oshogbo & 60,000 & 0.055 & 19 & 0.43 & 170603.791 & 26776.265 & 7182058.7 & 928786.1387 \\
Aba & 131,000 & 0.055 & 19 & 0.38 & 372484.945 & 51663.662 & 15680828 & 2014478.436 \\
Jos & 90,000 & 0.055 & 19 & 0.53 & 255905.687 & 49504.955 & 10773088 & 1387529.363 \\
Warri & 55,000 & 0.055 & 19 & 0.69 & 156386.809 & 39386.018 & 6583553.8 & 852328.9347 \\
Gusau & 69,000 & 0.055 & 19 & 0.43 & 196194.36 & 30792.705 & 8259367.5 & 1066409.106 \\
Potiskum & 30,988 & 0.055 & 19 & 0.56 & 88111.1715 & 18009.923 & 3709293.9 & 485150.8579 \\
Uyo & 12,909 & 0.055 & 19 & 0.78 & 36705.4057 & 10450.029 & 1545219.9 & 208696.8994 \\
Suleja & 11,590 & 0.055 & 19 & 0.64 & 32954.9657 & 7698.28 & 1387334.3 & 188527.489 \\
New Bussa & 7,322 & 0.055 & 19 & 0.21 & 20819.3494 & 1595.8031 & 876450.56 & 123263.6196 \\
\hline
\end{tabular}

Source: The estimates reported here are obtained using spreadsheet computation procedures 
$\mathrm{P}=\mathrm{P}_{\mathrm{o}} \mathrm{e}^{\mathrm{kt}}$

where $\mathrm{P}$ stands for the population of the urban centre at a future date, $\mathrm{P}_{\mathrm{o}}$ the initial population, $t$ the number of years between the initial and future date, $k$ the rate of growth and $\mathrm{e}$ is an exponential function (Oluwande, 1983).

The procedure and the parameters used in Estimating the 2050 Solid Waste Generation Pattern for Nigerian Urban Centres as shown in Table 3 could be discussed as follows;

$P_{1963}=$ The population of the chosen urban centres as at 1963 .

$\mathrm{t}=$ The time lag between 1963 and 1982 obtained as 19 years.

$k=$ The population growth rate for Nigerian urban centres obtained from "The State of the World Population" published by the United Nations Population Fund.

$\mathrm{GRCD}_{1982}=$ The 1982 domestic solid waste generation rate per capita per day for the chosen urban centres.

$\mathrm{EP}_{1982}=$ Estimated 1982 population for the chosen urban centres obtained as $\mathrm{EP}_{1982}=\mathrm{P}_{1963} \mathrm{e}^{\mathrm{kt}}$

$\mathrm{EDGV}_{1982}=$ Estimated 1982 domestic solid waste generation volume in tonnes per year for the chosen urban

centres obtained as EDGV $=0.365 \mathrm{EP}_{1982} \mathrm{GRCD}_{1982}$

$\mathrm{EP}_{2050}=$ Estimated 2050 population for the chosen urban centres obtained as $\mathrm{EP}_{2050}=\mathrm{P}_{1982} \mathrm{e}^{\mathrm{kt}}$

$\mathrm{EDGV}_{2050}=$ Estimated 2050 domestic solid waste generation volume in tonnes per year for the chosen urban centres obtained using the modelling equation $\mathrm{EDGV}_{2050}=11299.69+0.127747 \mathrm{EP}_{1982}$ derived by running an ordinary least square regression (OLS) for the 1982 estimated

\section{$5 \quad$ Result and discussion}

The estimation equation, $\mathrm{EDGV}_{2050}=11299.69+0.127747 \mathrm{EP}_{1982}$ enable us to predict what the volume of domestic solid waste generated is likely to be in midtwenty first century for any Nigerian urban centre once we know the population of the urban centre at year 2050. The data and estimation results presented in this study is useful for the various agencies responsible for solid waste management in Nigerian urban centres for planning purposes in their efforts to minimise health hazards from indiscriminate solid waste disposal.

With the estimated solid waste generation volume and population in Nigerian urban centres by 2050 , an estimate of the capital overhead and operating cost needed to manage this volume of waste could be computed in the planning horizon and appropriate budget allocation made. 


\section{Conclusion and recommendations}

The estimated volume of domestic solid waste generation by 2050 is a clear evidence that the magnitude of waste likely to be generated in Nigerian urban centres and mega-cities are bound to be enormous.

Considering the changes taking place in the economy of the nation, all the indications are for rapid increase in the rate of urbanisation and consequently, in the rate at which solid waste are likely to be generated.

Hence, unless some drastic changes takes place in the technological, organisational and financial arrangements for dealing with this vastly increased volume, environmental condition in Nigerian urban centres and mega-cities promise to suffer degradation even more drastically in the mid-21 $21^{\text {st }}$ Century and our dream of sustainable development might be a mirage as we proceed into the new millenium.

The following recommendations are hereby suggested for improved and cleaner environment;

(a) The various agencies responsible for solid waste

management in Nigerian urban centres should make concerted plan to attract more consistent budgetary allocation based on the estimated solid waste generation volume.

(b) There is a need to improve on the current conservative policy option with regard to public education. The abject level of environmental deterioration noticeable in Nigerian urban centres gives a strong impression that the current state of knowledge of the general public regarding public health matters is very low.

(c) Caution should also be exercised in the choice of refuse depots and dump sites by the various agencies handling solid waste in Nigerian urban centres to ensure that solid waste disposal do not pose health hazards.

(d) There is a need for supported active Research into waste minimisation strategies in Nigerian urban centres as we advance into the new millenium.

\section{References}

[1] World Bank, World Development Report 1993: Investing in Health, Washington, DC, The World Bank, 1983

[2] Holmes, R, The Water Balance Method of Estimating Leachate Production from Landfill Sites, Solid Wastes, 70, pp. 21 - 33, 1980.

[3] FMHE, The State of The Environment in Nigeria, Monograph Series No. 2, Federal Ministry of Housing and Environment, Environmental Planning and Protection Division, 1982

[4] Osuocha, P.C, Improving Refuse Management in Urban Nigeria, Proceedings of the 25th WEDC Conference, Addis Ababa, Ethiopia, $30^{\text {th }}$ August $-3^{\text {rd }}$ September, 1999, pp. 339-341, 1999. 
[5] Sangodoyin A.Y, Assessment of the adequacy of a Water Treatment Process by in-plant Monitoring, International Journal of Environmental Studies, 48, pp. 257 -262, 1995.

[6] Pickford, J, Solid Wastes in Hot Climates, In Water, Wastes and Health in Hot Climates, R. Feachem, R. McGarry and D. Mara (eds), John Wiley and Sons, Chichester, 1978.

[7] UNU, United Nations University Newsletter, Tokyo, 7 (2), 9, 1983.

[8] UNEP, Fresh-Water Pollution, UNEP/GEMS Environment Library, No. 6, UNEP, Nairobi, Kenya, 1991.

[9] KAJOGBOLA, D.O, Small Scale Enterprises andthe Environment: A Case Study of Packaged Water Industry in Ibadan Region, Nigeria, Nigerian Environmental Study Action Team, 1998.

[10] FMH, National Health Policy Report, Federal Ministry of Health, Nigeria, 1986

[11] Benka-Coker, M.O and Bafor, B.E, Waste Management and Water Pollution, Proceedings of the 25th WEDC Conference, Addis Ababa, Ethiopia, 30 ${ }^{\text {th }}$ August $-3^{\text {rd }}$ September, 1999, pp. 320-322, 1999.

[12] FOS , Federal Office of Statistics Yearbook, Federal Government of Nigeria, 1996.

[13] ECA, Economic Report on Africa 1999, The Challenge of Poverty Reduction and Sustainability, Economic Commission for Africa, Addis Ababa, Ethiopia, 1999.

[14] UNPF, The State of The World Population, United Nations Population Fund, pp. 70-72, 1994.

[15] Oluwande, P.A, Guide to Tropical Environmental Health Engineering, Nigeria Institute for Social and Economic Research (NISER), Ibadan, Nigeria, 1983. 